OTHER

\title{
The Carbon Bubble
}

By Jeff Rubin. 2015. Random House Canada, 320 Front Street West, Suite 1400, Toronto, ON, Canada, M5V 3B6. 246 pages, 32.00 CAD, Cloth.

A fascinating easy-to-read analysis of the science, economics, and politics of Canadian oil sands development that considers local, national, and global issues. Rubin explains complex interconnected issues of climate change and oil sands development in a way that is accessible without insulting your intelligence. Traditional thinking assumes development must always be linked with increased carbon emissions. Consequently anything that would limit carbon emissions (such as a cap or tax on emissions or, in the case of Canada, labeling oil sands as an excessive emitter of carbon) is considered to have negative consequences for economic growth and is thus labeled as a "bad" for Canada's Gross Domestic Product (GDP)!

Rubin shows however that increasingly there are examples of increased economic growth with technological strategies that increase GDP while simultaneously reducing carbon emissions, hence "green growth".
There is consensus the world should not let the global average temperature increase more than two degrees Celsius; thus there is a fixed carbon budget that is defined by the two degree threshold. More progressive thinking rejects an economic future based on high carbon emissions such as oil sands development. Rubin's documentation of the now largely bankrupt coal industry is a clear wake-up call for the most carbon intensive of all oil production, oil sands, clearly the industry next in line when it comes to regulating the big emitters.

As most of us already know, Canada is increasingly occupying a unique position globally - a country that ignores global concern and actions on Climate Change and which banks economic development on conventional carbon energy sources. Rubin's book is a much needed wake up call.

Brent Tegler 